\title{
Crohn's disease in the city of Derby, 1951-85
}

\author{
I W Fellows, J G Freeman, G K T Holmes
}

\begin{abstract}
An epidemiological survey of Crohn's disease in the city of Derby showed that the incidence of the condition increased from $0.7 / 10^{5}$ per year between 1951 and 1955 to $6 \cdot 67 / 10^{5}$ per year between 1981 and 1985 but seemed to reach a plateau between 1976 and 1985. Large bowel Crohn's disease was more common in patients presenting aged 60-79 years than in those aged 20-39 years. The increase in incidence was not solely due to the detection of milder disease. There was no evidence that the Asian (Indian subcontinent) population of Derby was resistant to the development of Crohn's disease.
\end{abstract}

While many surveys of the epidemiology of Crohn's disease in the United Kingdom have been published, most recent reports come from coastal areas $^{1-4}$ and few cover a period long enough to show trends in incidence of this disease $^{14}$ since the 1950s. The purpose of this study was to determine the epidemiology of Crohn's disease in an inland British city over 35 years.

\section{Patients and methods}

This survey began in 1978 and was performed retrospectively for the years 1951 to 1978 inclusive, and prospectively from 1978 onwards. Cases of Crohn's disease were sought by reference to records held by hospital activities analysis, the department of histopathology, and consultants in the two hospitals serving the city of Derby - the Derbyshire Royal Infirmary and the Derby City Hospital. Histopathology records, which were all available for scrutiny, indexed Crohn's disease over this whole period. The case notes of patients were reviewed in either their original form or on microfilm. The nearest other large hospitals are 15 miles away, in Nottingham, and review of hospital activities analysis for Nottingham did not disclose any cases of Crohn's disease in inhabitants of the city of Derby who were treated solely in the hospitals of Nottingham. The case notes of all patients were reviewed by one author (IWF). Criteria accepted as indicative of Crohn's disease were similar to those of Binder $e t a l,{ }^{5}$ namely:

(a) Case history of abdominal pain or diarrhoea for more than three months;

(b) Radiological evidence of stenoses in the small bowel or segmental colitis with cobblestone changes in the large bowel;

(c) Histological evidence of transmural inflammation or granulomas with Langhan's giant cells, or both

Patients with acute ileitis were excluded. All patients had chronic symptoms and objective evidence of radiological or histological abnor- mality, or both. Cases of infectious disease were excluded by stool culture. Although stool cultures are not available for all patients, the chronicity of symptoms and regular prolonged follow up make infectious aetiologies very unlikely. Cases of Crohn's disease diagnosed in patients before moving to Derby were also excluded from analysis of incidence.

The city of Derby comprises an urban population which, according to the Registrar General's mid-year estimates and census data, varied from 196256 in 1951 to 215300 in 1985. There were boundary changes resulting in an enlargement of the city in 1968 but the population figures before then are corrected allowing for these changes and cases of Crohn's disease arising before 1968 outside the old city boundaries are counted as arising in the city. The male:female ratio in 1981 was $1: 1.033$ compared with $1: 1.035$ in 1961 and 1:1.031 in 1971. Incidence figures of Crohn's disease for each year were calculated by reference to the Registrar General's mid-year estimates for the population of the city of Derby. The mean incidence was calculated for successive five year periods and for patients by decile of age. The prevalence of Crohn's disease was calculated at the end of the study (31 December 1985). Residence in Derby was confirmed either by review of the notes or by contacting general practitioners.

Data on the incidence and prevalence of Crohn's disease in West Indians have been published previously. ${ }^{6}$ Data on the incidence and prevalence of Crohn's disease in Asians were calculated by reference to estimates of the population of Asians in the city of Derby obtained from the local Council for Racial Equality. This suggests a population of 19000 Asians (Indians and Pakistanis) in 1982. This is considered to be a more accurate figure than that of persons residing in households with an Asian born head of household derived from the 1981 census (12 152 persons) because second generation Asians born in this country would have been classified as United Kingdom born heads of household.

Statistical analysis was performed by $\chi^{2}$ test, using Yates's correction, and $95 \%$ confidence intervals were calculated after Fleiss.?

\section{Results}

ONSET-DIAGNOSIS INTERVAL

The time from onset of symptoms to diagnosis of Crohn's disease was calculated for the periods $1951-9,1960-9,1970-9$, and 1980-5, to the nearest month. There was no significant difference in the time elapsed before diagnosis during the period of this survey. For the period 1951-9, median time to diagnosis was 3 months (range 0 to 144 months); 1960-9, median 7.5 months
Dr G K T Holmes, Derbyshire Royal Infirmary, London Road, Derby.

Accepted for publication

2 January 1990 


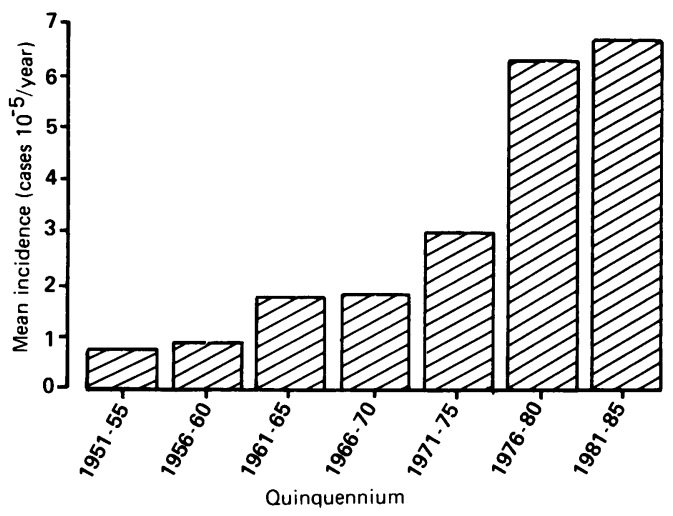

Figure 1: Incidence of Crohn's disease for successive quinquennia, from 1951-85.

(range 0 to 144 months); 1970-9, median 5 months (range 0 to 168 months); $1980-5$, median 8 months (range 0 to 324 months). This suggests that differences in incidence of Crohn's disease during this study could not be explained by changes in the time to achieve the diagnosis.

\section{INCIDENCE}

A total of 225 people were identified as developing Crohn's disease in the years 1951-85 inclusive. The annual incidence for each quinquennium is shown in Figure 1. The male: female ratio was $99: 126(1: 1 \cdot 27)$, and did not differ significantly between the years 1951-69 $(1: 1 \cdot 67)$ and $1970-85(1: 1 \cdot 2)$. In the 60 or over age groups, the male:female ratio was $18: 25$ $(1: 1 \cdot 39)$, a value not significantly different from the rest of the population. Mean incidence over successive five year periods shows a progressive rise from $0 \cdot 7 / 10^{5}$ per year $(1951-5)$ to $6 \cdot 67 / 10^{5}$ per year (1981-5). Age specific incidence (by decile of age and successive quinquennia) is

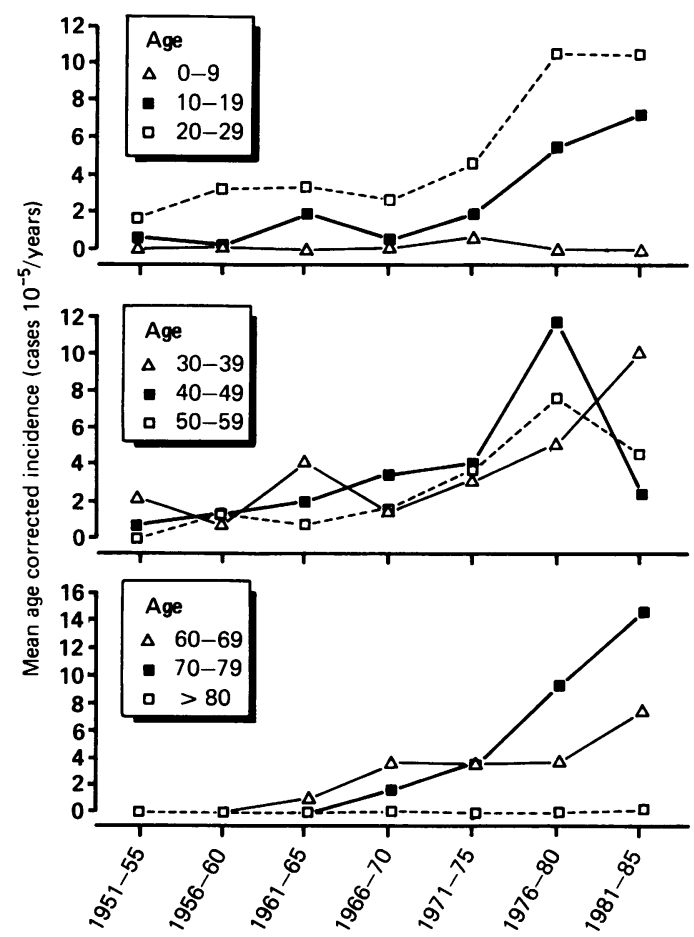

Figure 2: Age specific incidence (by decile of age) for successive quinquennia, 1951-85.
TABLE I Crohn's disease in Derby. Age standardised $\star$ incidence (95\% confidence intervals)/5 years per 100000

\begin{tabular}{lcc}
\hline & Men & Women \\
\hline $1951-5$ & $2 \cdot 12(-0 \cdot 83-5 \cdot 1)$ & $5 \cdot 36(0 \cdot 58-10 \cdot 1)$ \\
$1956-60$ & $4 \cdot 84(0 \cdot 56-9 \cdot 1)$ & $3 \cdot 89(-0 \cdot 03-7 \cdot 8)$ \\
$1961-5$ & $5 \cdot 02(0 \cdot 59-9 \cdot 5)$ & $12 \cdot 09(5 \cdot 4-18 \cdot 8)$ \\
$1966-70$ & $7 \cdot 48(2 \cdot 3-12 \cdot 7)$ & $9 \cdot 67(3 \cdot 9-15 \cdot 4)$ \\
$1971-5$ & $13 \cdot 13(6 \cdot 2-20 \cdot 1)$ & $16 \cdot 44(8 \cdot 8-24 \cdot 1)$ \\
$1976-80$ & $35 \cdot 11(23 \cdot 8-46 \cdot 4)$ & $28 \cdot 45(18 \cdot 4-38 \cdot 5)$ \\
$1981-5$ & $26 \cdot 57(16 \cdot 7-36 \cdot 4)$ & $40 \cdot 39(28 \cdot 5-52 \cdot 3)$ \\
\hline
\end{tabular}

^Each sex standardised respectively to Derby male and female population estimates for 1981-5.

shown in Figure 2. The age standardised incidence for each sex is shown in Table $I$ and age specific incidence for each sex 1976-85 is shown in Table II. Over the period of the study there was a gradual increase in incidence and then a sudden rise for 1976-80, which was evident in both sexes. Over the last five year period there was no overall increase, for a continuing rise in women was offset by a fall in the rate for men (Table I).

\section{PREVALENCE}

The prevalence of Crohn's disease in Derby at the end of 1985 was 85 per $10^{5}$. This figure allows for migration of cases into and out of the city as well as patients who have died.

\section{SITE OF DISEASE}

The small bowel alone was involved in 53 patients, the large bowel alone in 65 , while mixed small and large bowel disease was present in 107. The first case of colonic Crohn's disease was recognised in 1965. Since then, there has been a noticeable rise in the incidence of pure colonic Crohn's disease in Derby, especially from 1979 onwards (Fig 3). Between 1951 and 1969, seven of $50(14 \%)$ diagnoses showed disease affecting the large bowel only compared with 57 of 175 (33\%) diagnoses made between 1970 and 1985 $(\mathrm{p}<0.01)$.

The mean incidence of large bowel disease was greater in patients between 60 and 79 years $(1.90 /$ $10^{5}$ per year, $95 \%$ confidence intervals $1 \cdot 24-2 \cdot 87 /$ $10^{5}$ per year) compared with patients aged 20-39 years $\left(0.91 / 10^{5}\right.$ per year, $95 \%$ confidence intervals $0.56-1.47 / 10^{5}$ per year), $\mathrm{p}<0.025$ (Fig 4).

The mean incidence of combined small and large bowel disease was higher in patients aged $20-39$ years $\left(2 \cdot 63 / 10^{5}\right.$ per year, $95 \%$ confidence

TABLE II Crohn's disease in Derby. Sex and age specific incidence/100000 for 1976-85

\begin{tabular}{lcllll}
\hline & \multicolumn{2}{l}{ Men } & \multicolumn{2}{l}{ Women } \\
\cline { 2 - 3 } \cline { 5 - 6 } Age $(y r s)$ & No & Incidence & & No & Incidence \\
\hline $0-9$ & 0 & 0 & & 0 & 0 \\
$10-19$ & 15 & $8 \cdot 1$ & & 8 & $4 \cdot 5$ \\
$20-29$ & 12 & $7 \cdot 8$ & & 20 & $13 \cdot 4$ \\
$30-39$ & 11 & $7 \cdot 9$ & & 10 & $7 \cdot 4$ \\
$40-49$ & 6 & $5 \cdot 0$ & & 11 & $9 \cdot 4$ \\
$50-59$ & 9 & $6 \cdot 9$ & & 7 & $5 \cdot 4$ \\
$60-69$ & 4 & $3 \cdot 8$ & & 8 & $7 \cdot 0$ \\
$70-79$ & 8 & $13 \cdot 2$ & & 10 & $11 \cdot 1$ \\
>80 & 0 & 0 & 1 & $2 \cdot 5$ \\
All ages (standardised & & $6 \cdot 2(4 \cdot 7-7 \cdot 7)$ & & $6 \cdot 9(5 \cdot 3-8 \cdot 4)$ \\
to total Derby & & &. & & \\
population 1981) & & & & & \\
\hline
\end{tabular}




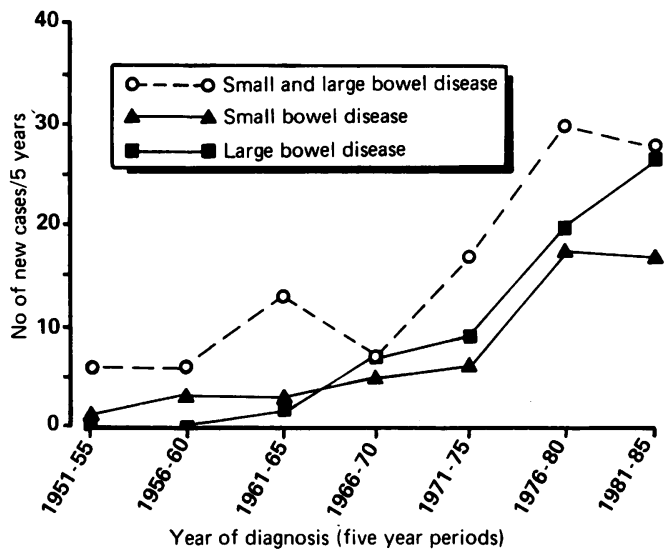

Figure 3: Total number of new cases of Crohn's disease for successive quinquennia, 1951-85, by site of disease - small and large bowel disease, small bowel disease, and large bowel disease.

intervals $1 \cdot 99-3 \cdot 48 / 10^{5}$ per year) than in patients aged $60-79$ years $\left(0 \cdot 63 / 10^{5}\right.$ per year, $95 \%$ confidence intervals $0 \cdot 29-1 \cdot 3 / 10^{5}$ per year), $\mathrm{p}<0.001$ (Fig 4).

PROOF OF DIAGNOSIS

Proof of the diagnosis of Crohn's disease on the basis of radiological evidence with no histological proof became more common during the survey. From 1951-69, radiological proof alone was obtained in three of $50(6 \%)$ diagnoses, while from 1970 to 1985,61 of 175 (35\%) diagnoses were based on radiological confirmation only $(\mathrm{p}<0.01)$. There was histological confirmation alone of the diagnosis in 61 patients, while both histological and radiological confirmation of the diagnosis was obtained in 100 . Histological proof alone became less common from 1951-69 (21 of 50 diagnoses) compared with 1970-85 (40 of 175 diagnoses $)(p<0.01)$. There was no change in the frequency with which the diagnosis was corroborated by both radiological and histological criteria during the period of this study.

Barium radiology was performed more frequently later in the survey, with 35 of 50 patients diagnosed between 1951 and 1969 undergoing this investigation compared with 156 of 175 diagnosed between 1970 and $1985(\mathrm{p}<0.01)$.

The number of patients who underwent surgical resection increased progressively (Table III).

\section{CROHN'S DISEASE IN ASIANS}

Six cases of Crohn's disease were diagnosed in Asians. Patient 2 had been treated for spinal tuberculosis five years before developing Crohn's disease. He had received a two year course of antituberculosis chemotherapy and showed no evidence of recurrence. Chest radiography on patients 2-6 was normal but patient 1 showed evidence of apical pulmonary scarring due to old tuberculosis. There was no evidence of

TABLE III Number of patients undergoing surgical bowel resection by quinquennium of diagnosis
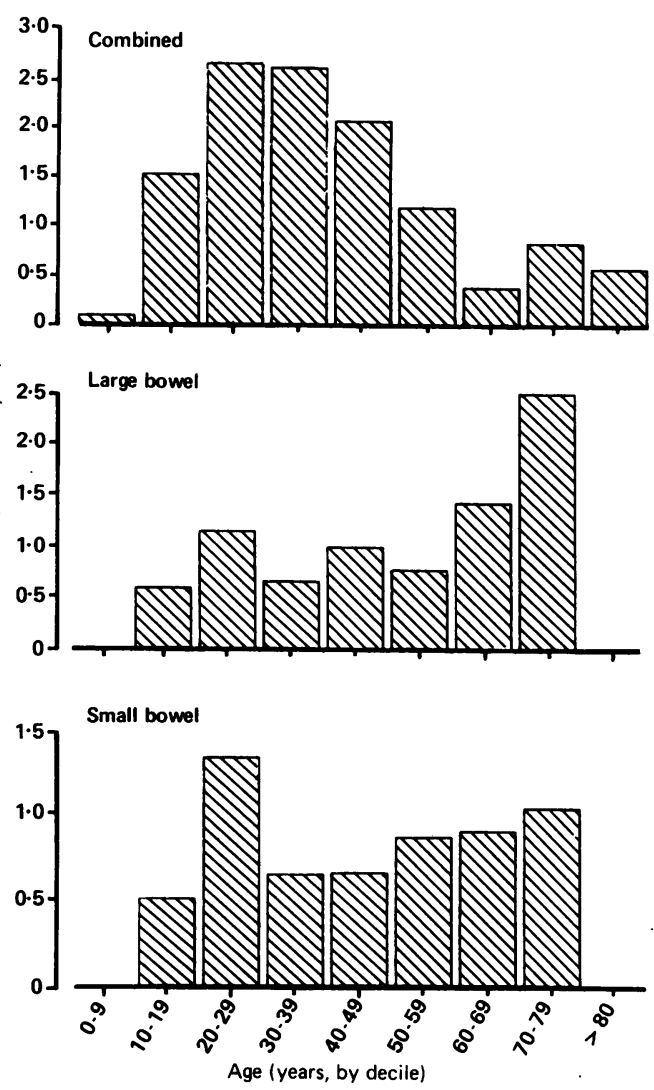

Figure 4: Age specific incidence (by decile of age) of combined small and large bowel Crohn's disease, colonic Crohn's disease, and small bowel Crohn's disease, 1951-85.

bowel tuberculosis in any of these patients, either on histology or on culture of resected bowel. Only limited follow up is available in patient 1 but patients 2-6 had not developed tuberculosis during follow up (to 1988) after developing Crohn's disease. One case was diagnosed in each of the years 1966 and 1980, 1983 and 1984 while two cases were diagnosed in 1985 (Table IV). Using an estimate of 19000 Asians living in Derby, the mean incidence of Crohn's disease in this group was $4 \cdot 39 / 10^{5}$ per year $(95 \%$ confidence intervals $1 \cdot 61-10 \cdot 88 / 10^{5}$ per year) for $1980-85$, compared with a mean incidence of $7 \cdot 47 / 10^{5}$ per year $(95 \%$ confidence intervals $6.03-$ $9 \cdot 25 / 10^{5}$ per year) for the general population, estimates which are not significantly different.

\section{Discussion}

This survey has shown a considerable increase in the incidence of Crohn's disease in the city of Derby over the period 1951-85 with particular increases in ileocolic disease in the $10-49$ year old group, and of pure colonic disease in the 60-79 year old group.

These changes in incidence are similar in magnitude to those observed in the Cardiff series' but the increase is delayed by approximately 10 years. This contrasts with the reduction in the incidence of Crohn's disease reported in Aberdeen between 1973 and 1975.' The incidence data are similar to those recorded in the Nottingham series from 1958 to $1972 .{ }^{8}$ Over the last 10 years, the incidence of Crohn's disease in Derby seems to have reached a plateau. There has been a reduction in the proportion of patients

$1951-5 \quad 1956-60 \quad 1961-5 \quad 1966-70 \quad 1971-5 \quad 1976-80 \quad 1981-5$

18

$30 \quad 31 \quad 33$


TABLE IV Clinical data on six Asian patients presenting in Derby with Crohn's disease

\begin{tabular}{|c|c|c|c|c|c|c|c|c|c|c|}
\hline \multirow[b]{3}{*}{ Case No } & \multirow{3}{*}{$\begin{array}{l}\text { Year of } \\
\text { presentation }\end{array}$} & \multirow{3}{*}{$\begin{array}{l}\text { Age at } \\
\text { presentation }\end{array}$} & \multirow[b]{3}{*}{ Sex } & \multirow[b]{3}{*}{ Birthplace } & \multirow{3}{*}{$\begin{array}{l}\text { Arrival } \\
\text { in } U K\end{array}$} & \multirow{3}{*}{$\begin{array}{l}\text { Parents' } \\
\text { birthplace }\end{array}$} & \multirow{2}{*}{\multicolumn{2}{|c|}{ Diagnostic criteria }} & \multicolumn{2}{|c|}{ Site of disease } \\
\hline & & & & & & & & & \multirow{2}{*}{$\begin{array}{l}\text { Small } \\
\text { intestine }\end{array}$} & \multirow{2}{*}{$\begin{array}{l}\text { Large } \\
\text { intestine }\end{array}$} \\
\hline & & & & & & & Radiological & Histological & & \\
\hline 1 & 1966 & 63 & $\mathbf{M}$ & India & $?$ & India & - & + & + & - \\
\hline 2 & 1980 & 51 & $\mathbf{M}$ & India & 1969 & India & - & + & - & + \\
\hline 3 & 1983 & 16 & $\mathbf{F}$ & Derby & - & India & + & + & + & + \\
\hline 4 & 1984 & 15 & $\mathbf{F}$ & Derby & - & India & - & + & + & + \\
\hline 5 & 1985 & 76 & $\mathbf{F}$ & Pakistan & 1982 & Pakistan & + & + & + & + \\
\hline 6 & 1985 & 20 & $\mathbf{F}$ & London & - & India & + & + & + & + \\
\hline
\end{tabular}

who have undergone surgical bowel resection, suggesting that the increase may have been partly due to the detection of milder disease. The number of patients requiring surgical resection of the bowel has also increased, however, indicating that the rise in incidence of Crohn's disease is not solely due to detection of milder disease. Detection of mild cases could account for some of the increase in incidence seen in older patients, although the propensity of the latter to have pure colonic disease suggests that they differ in site of disease rather than having previously undetected mild disease. The series also indicates changes in medical practice, with patients being investigated by barium contrast radiology more frequently in the recent years than during the 1950 s.

There was no difference in the incidence of Crohn's disease in Asians compared with the rest of the series in the last six years of the survey. Although the small numbers could lead to a type 2 statistical error, there is no evidence from this study that Asians are genetically protected against the development of Crohn's disease or that they avoid exposure to any causal environmental agents. This is similar to our previously published work that West Indians are not genetically resistant to the development of Crohn's disease. ${ }^{6}$ There have been few reports of Crohn's disease in Asians in the United Kingdom. Keshavarzian et $a l^{9}$ reported six anecdotal cases, but did not study a defined population and so were unable to determine incidence or prevalence.

In common with other groups, ${ }^{10}$ we have found a noticeable increase in colonic Crohn's disease in the elderly, and in the last five years of the survey, 1981-5, the highest age specific incidence of Crohn's disease was found in the age group 70-79 years. Unlike Fabricius et al ${ }^{10}$ we found there were more women among patients diagnosed as having Crohn's disease at 60 years or older, as indicated by other groups. ${ }^{11-13}$
The incidence and prevalence of Crohn's disease in Derby is one of the highest reported in the world. The work of Ballantyne et $a l^{14}$ suggests, however, that the inclusion of symptomatic cases of inflammatory bowel disease may underestimate the prevalence by at least $30 \%$, as judged by their detection of asymptomatic cases in subjects being screened by faecal occult blood tests. It is not known whether detection of these cases represents early diagnosis of patients who will become symptomatic later or whether these constitute a reservoir of permanently subclinical disease.

We thank Dr R F A Logan, Department of Community Medicine and Epidemiology, University of Nottingham Medical School, for his assistance in the statistical analysis of results.

1 Rose JDR, Roberts GM, Williams G, Mayberry JF, Rhodes J. Cardiff Crohn's disease jubilee: the incidence over 50 years. Gut 1988; 29: 346-51.

2 Lee FI, Costello FT. Crohn's disease in Blackpool - incidence and prevalence 1968-1980. Gut 1985; 26: 274-8.

3 Devlin HB, Datta D, Dellipiani AW. The incidence and prevalence of inflammatory bowel disease in North Tees Health District. World f Surg 1980; 4: 183-93.

4 Kyle J, Stark G. Fall in the incidence of Crohn's disease. Gut $1980 ; 21: 340-3$.

5 Binder V, Both H, Hansen PK, Hendricksen C, Kreiner S Torp-Pedersen $\mathbf{K}$. Incidence and prevalence of ulcerative colitis and Crohn's disease in the County of Copenhagen 1962 to 1978. Gastroenterology 1982;93: 563-8.

6 Fellows IW, Mayberry JF, Holmes GKT. Crohn's disease in West Indians. Am f Gastroenterol 1988; 83: 752-5.

7 Fleiss J. Statistical methods for rates and proportions. 2nd ed. New York: Wiley, 1981: 14-5, 29-30.

8 Miller DS, Keighley AC, Langman MJS. Changing patterns in epidemiology of Crohn's disease. Lancet 1974; ii: 691-3.

9 Keshavarzian A, Gupta S, Saverymuttu SH, Hodgson HJF Are there ethnic differences in inflammatory bowel disease? Indian $\mathcal{F}$ Gastroenterol 1986; 5: 95-7.

10 Fabricius PJ, Gyde SN, Shouler P, Keighley MRB Alexander-Williams J, Allan RN. Crohn's disease in the elderly. Gut 1985; 26: 461-5.

11 Carr N, Schofield PF. Inflammatory bowel disease in the older patient. Brf Surg 1982; 69: 223-5.

12 Myren J, Gjone E, Hertzberg JN, Rygivold O, Semb LS Fretheim B. Epidemiology of ulcerative colitis and regional Fretheim B. Epidemiology of ulcerative colitis and regional enterocolitis (Crohn's

13 Tchirkow G, Lavery IC, Fazio VW. Crohn's disease in the elderly. Dis Colon Rectum 1983; 26: 171-81.

14 Ballantyne KC, Mayberry JF, Pye G, Mangham C, Hardcastle JD. Detection of asymptomatic inflammatory bowel disease while screening for colorectal cancer [Abstract]. Gut 1987; 28: A1392. 